\title{
The spectrum of myocardial homeostasis mechanisms in the settings of cardiac surgery procedures (Review)
}

\author{
EMMANUEL PAPADAKIS ${ }^{1}$, MELETIOS KANAKIS ${ }^{2}$, AGAPI KATAKI ${ }^{3}$ and DEMETRIOS A. SPANDIDOS ${ }^{4}$ \\ ${ }^{1}$ Department of Cardiac Surgery, Onassis Cardiac Surgery Center, 17674 Athens, Greece; ${ }^{2}$ Cardiothoracic Surgery Unit, \\ Great Ormond Street Hospital for Children, WC1N 3JH London, UK; ${ }^{3}$ Propaedeutic Surgery First Department, \\ University of Athens, 11527 Athens; ${ }^{4}$ Laboratory of Clinical Virology, Medical School, \\ University of Crete, 71003 Heraklion, Crete, Greece
}

Received October 25, 2017; Accepted November 28, 2017

DOI: $10.3892 / \mathrm{mmr} .2017 .8174$

\begin{abstract}
Classic cardiac surgery, determined through the function of cardiopulmonary bypass machine and myocardial cardioplegic arrest, represents the most controlled scenario for cardiomyocyte homeostatic disturbances due to systemic inflammatory response and myocardial reperfusion injury. An increasing number of studies have demonstrated that myocardial cell homeostasis in cardiac surgery procedures is a sequence of molecularly interrelated and overlapping mechanisms in the form of apoptosis, autophagy and necrosis, which are activated by a plethora of induced inflammatory mediators and gene-related signaling pathways. In this study, we outline the molecular mechanisms of the cardiomyocyte adaptive homeostatic process and the associated clinical implications, in the settings of classic cardiac surgery procedures.
\end{abstract}

\section{Contents}

1. Introduction

2. Mechanisms of myocardial cell death: Autophagy, apoptosis, and necrosis

3. Principles of cardiomyocyte apoptosis

4. Principles of cardiomyocyte autophagy

5. Myocardial cell homeostasis in cardiac surgery era

6. Myocardial homeostasis in current cardiac surgery settings

7. Conclusions

Correspondence to: Dr Emmanuel Papadakis, Department of Cardiac Surgery, Onassis Cardiac Surgery Center, 17674 Athens, Greece

E-mail: emg.papadakis@gmail.com

Key words: cardiac surgery patient, myocardial reperfusion injury, myocardial homeostasis in cardiac surgery, cardioplegic arrest, cardiopulmonary bypass

\section{Introduction}

Cardiovascular diseases in the twilight of the 21st century, account for more than $33 \%$ of all human mortality and remain the leading cause of human mortalities worldwide (1). In addition to the extension of the expected lifespan over the last few decades and the prolongation of life expectancy in the future, the prevalence of age-related diseases, such as cardiomyopathies are expected to be raised. Despite recent advances in the medical treatment of heart diseases, the cohort of patients requiring surgical treatment, particularly the elderly, is on the increase (2).

During cardiac surgery procedures, despite the meticulously applied intraoperative cardioprotective techniques, myocardial ischemia remains, resulting in the expansion of molecular sequences of cardiomyocyte reperfusion injury, exhibited as myocardial arrhythmias, infarction, low cardiac output or even death in the early postoperative course of cardiac surgery patients (3).

The aim of the present study is to outline the molecular mechanisms underlying the operative cardiomyocyte adaptive homeostatic process and the associated clinical implications, in the settings of cardiac surgery procedures.

2. Mechanisms of myocardial cell death: Autophagy, apoptosis, and necrosis

Cell death, the biological event where the cell ceases to carry out its functions, may originate from three different cellular mechanisms, namely: Apoptosis, autophagy and necrosis. Cardiomyocyte death, either progressive or acute, constitutes a hallmark of various cardiac diseases, such as heart failure, myocardial infarction and ischemia reperfusion injury $(4,5)$. Cardiac surgery procedures are conjoined with a number of myocardial stress stimuli, such as ischemia-reperfusion, cardioplegic arrest, oxidative product agents, inflammatory mediators and surgical trauma, which trigger the mechanism of myocardial cell death (6).

All three of the cell death mechanisms have been identified in cardiomyocyte death during the progression of myocardial injury in cardiac surgery procedures $(7,8)$. Physiologic aging-related cell death primarily occurs by means of an evolutionariily preserved form of cell suicide termed apoptosis. 
'Apoptosis', derived from the Greek term 'apo - ptosis' means 'the fall of tree leaves', was first introduced in 1972 to determine a natural form of cell death that occurs in multicellular organisms (9). It constitutes a programmed cell death process that is energy-dependent, precisely regulated and genetically directed. The mechanism of apoptosis belongs to the extreme cell's defense system against the accumulated damaged and aged proteins subjected to a persistent degradation process. It has been estimated that 50-70 billion cells die each day in the average human adult due to the apoptotic process (8).

A variety of myocardial pathologies, such as myocardial ischemia-infarction, dysrhythmias, or myocardial contractile dysfunction, are associated with an increasing number of proapoptotic stimuli that have been identified to promote cardiomyocyte apoptosis. A group of proapoptotic stimuli, including: Ischemia, reperfusion injury, cellular calcium $\mathrm{Ca}^{2+}$ overload, oxygen-free radicals, tumor necrosis factor (TNF)- $\alpha$, atrial natriuretic factor (ANF), pressure overload, increased levels of angiotensin II and catecholamine, as well as decreased Fas ligand and p53 levels, are involved in the induction of cardiomyocyte apoptosis (9).

Apoptotic bodies comprise dying apoptotic cells that are consequently engulfed by phagocytic cells and recycled to prevent an inflammatory response, while the morphological alterations of apoptotic cell death include cell shrinkage, plasma membrane bleeding, nuclear condensation, DNA fragmentation, and mRNA decay $(4,9)$.

In cardiac surgery procedures, the main stimuli for myocardial cell apoptosis may originate from myocardial ischemia and oxidative stress (intrinsic pathway) or from elevated inflammatory elevated humoral mediators released during cardiopulmonary bypass (CPB) (extrinsic pathway) $(10,11,12)$.

Autophagy is a Greek term 'auto - phagy' (eating oneself) that defines the destruction of the cytoplasm elements, organelles and aged proteins, in a programmed sequestration procedure, which finally isolates them in double membrane vesicles, termed autophagosomes. These autophagosomes are consequently transferred into lysosomes, where they are broken down within the lysosomatic acid hydroxylase action (13). Autophagy is a low-level continuous process in mammalian cells, serving as a 'housekeeper' for the destruction of dysfunctional proteins and organelles (14). Predominantly, autophagy has an adaptive role and acts as a defense mechanism to protect organisms against various pathologies including heart diseases, cancer and a number of neurodegenerative disorders, including Alzheimer's, Parkinson's and Huntington's disease $(15,16)$. Moreover, autophagy is involved in essential biological processes, such as tumorigenesis and differentiation, and is reduced with age $(17,18)$. Autophagy is impaired in the cardiorenal metabolic syndrome and suppressed by hyperlipidemia, hypercholesterolemia and obesity $(19,20)$. Insulin signaling may suppress the myocardial autophagic process and increase the propensity for left ventricular dysfunction in diabetic patients in the context of ischemia reperfusion injury (21). The process of autophagy seems to regulate both cell viability and death, thereby preserving cell homeostasis. However, in certain circumstances, it also serves to modulate cell death through the self-cannibalistic function of essential cellular components (22-24). The evolutionarily preserved cytoplasmic autophagy process is mainly regulated by 30 autophagy-related genes (Atgs), which have been cloned. Autophagy is induced via macro-autophagy, micro-autophagy and the chaperon-mediated autophagy pathways, in which heat shock cognate 70 -specific proteins are delivered to lysosomes by binding to the chaperone (25).

Macroautophagy is a common mechanism involved in mammalian cells and is generally referred to as autophagy. Mitochondrial autophagy (mitophagy) serves as a cytoprotective mechanism, which under normal conditions, recycles the damaged mitochondria, preserving ATP production and preventing apoptotic or necrotic cell death (26). In response to hypoxic or ischemic conditions, organs and cells show a multiple adaptive molecular metabolic process for their survival. Autophagy belongs to the exclusive hypoxic adaptation mechanisms that remove damaged mitochondria and misfolded proteins through a salvage lysosomal pathway in response to stress stimuli. It may be of the last mechanisms involved in cellular and organ ATP rescue in hypoxic conditions (27).

'Necrosis' is a term derived from the homonymous Greek word and means cell death by a savage, non-reversible and irregular degradation, as a result of profound disintegration of cell homeostasis (6).

Cell necrosis is defined by distinct morphological changes, including organelle swelling [endoplasmic reticulum (ER) and mitochondria], ATP loss, rupture of plasma membrane and enzymes leaking out of lysosomes into the cytoplasm, resulting in lysis and cell death necrosis. The release of cellular contents that typically follows necrotic cell death, triggers a secondary inflammatory cascade, unlike apoptosis or cell death. Apart from passive or accidental cell death secondary to physical or chemical trauma, emerging evidence suggests that a part of cell necrosis is regulated via serial signaling pathways, in a well-orchestrated cascade. A cohort of terms has been introduced to describe this form of necrosis, such as 'programmed necrosis', 'casp-independent cell death' and 'necroptosis' $(6,28)$. Molecular mechanisms that have been associated with cell execution include the enhancement of cytosolic $\mathrm{Ca}^{2+}$ and $\mathrm{Na}^{+}$concentrations of ROS accumulation, as well as mitochondrial permeability transition pore (MPTP) opening $(29,30)$.

On the other hand, in normal biological conditions, cell proliferation and death belong to the process of homeostasis. The term homoeostasis derived from the ancient Greek words 'homeo' and 'stasis', refers to the ability of an organic system to preserve its inner environmental stability, independently of the outer conditions. The rationale was first described in 1856 by the French physiologist Claude Bernard and was popularized in 1926 by the physiologist W. Cannon (31).

Under regular conditions, cell homeostasis remains stable secondary to adaptive autophagy, which metabolizes and recycles aged and aggregated misfolded proteins of the damaged cell (32). The mechanism belongs to the endogenous protective cellular mechanisms and is referred to as 'homeostatic intracellular repair response' (HIR ${ }^{2}$ ) (31). In case of autophagic mechanism insufficiency, the accumulated aged cellular proteins and pathological organelles lead to apoptosis or programmed cell death. By contrast, in case of excessive autophagic mechanism beyond a certain threshold, the cytosol and organelles are destroyed, paving the way 
for autophagic cell death (33). It has been suggested that the removal of destroyed cellular organelles and pathologically misfolded proteins follows the induction of the autophagic process and thus ATP production. Consequently, myocardial contractility is preserved, while apoptosis and cell death are suspended (34). In other words, cellular homeostasis may be preserved secondary to the balance between autophagy and the mechanisms of apoptosis (35).

\section{Principles of cardiomyocyte apoptosis}

Given that the mechanism of apoptosis is a regulated cellular 'altruist cell suicide', which supports the rest of the organism as a whole, it constitutes an essential component of development and organ homeostasis. In other words, it keeps the cell count and tissue 'diathesis' tendencies under control, both in normal and pathological conditions (36). Homeostasis in mammalians cells, regulated via cell growth and differentiation, also occurs from the process of apoptosis involvement (37). A sequence of molecular events is involved in apoptotic cell death activated by means of a cascade from at least 10 caspases, including cysteine, aspartic, and acid-specific protease (38).

Cardiomyocyte apoptosis is triggered by numerous signal pathways and regulated by multi-complicated extrinsic and intrinsic ligands. The intrinsic one is the main pathway and is also known as 'mitochondrial' due to the involvement of the mitochondrial cytochrome $c$. A wide spectrum of apoptotic signals, including oxidative stress, hypoxia, apoptosis-inducing factor (AIF), aberrant oncogene expression, p53 and DNA fragments activate the intrinsic pathway $(39,40)$.

The extrinsic apoptotic pathway is activated by death ligands, such as the Fas ligand or TNF- $\alpha$, which bind to analogous cell plasma membrane receptors (41). The $B c l$-2 gene family activates the intrinsic pathway and has pro-apoptotic properties due to Bax, Bak, Bnip3, as well as anti-apoptotic properties due to the $\mathrm{Bcl}-2$, and $\mathrm{Bcl}-\mathrm{x}$ proteins. It has been suggested that the determination of the cell towards the apoptosis cascade is dictated by the relative ratio of pro-apoptotic Bax to anti-apoptotic Bcl-2 proteins that are accumulated in the cell (42).

A cohort of systemic pathologies is associated with irregular apoptosis mechanism activation (43). In the cardiovascular system, apoptosis is involved in acute and chronic ischemic cardiomyopathies, idiopathic cardiomyopathies, myocardial infarction cell death, reperfusion injury, acute and chronic heart failure, arrhythmogenic right ventricular dysplasia, long-QT syndrome, coronary artery disease, and systemic atherosclerosis (44-48).

Ischemic myocardial conditions are the principal inducers of cardiac apoptosis. Myocardial infarct-associated apoptosis in humans has been predominantly found in the hypoperfused area between the focal infarct area and the non-ischemic myocardial tissue. It has been demonstrated that $12 \%$ of apoptotic cell death is found in the infarct zone and $1 \%$ in the non-ischemic area, suggesting the involvement of programmed cell death or apoptosis in myocardial infarction (49). Notably, the apoptotic process appears to participate in the remodeling procedure of a saphenous vein graft failure and it is encountered as a major determinant of restenosis graft development (50).
CPB during cardiac surgery initiates an acute systemic inflammation response secondary to the blood exposure on artificial surfaces of the bypass machine.

A variety of inflammatory mediators that bear proapoptotic stimuli properties include oxygen-free radicals, cytokine release, nitric oxide (NO), Fas ligand, TNF- $\alpha$, and neurohumoral factors, such as angiotensin II and p53 protein. These substances subsequently potentiate a cascade cellular response throughout the patient's body $(51,52)$.

Multiple organ dysfunction, encountered in the post-bypass syndrome, including myocardial, pulmonary, cerebral, and renal, seems to be secondary to the abovementioned overwhelming and overlapping inflammatory mediators and the systemic endothelial cell activation during CPB, which in turn may provoke apoptotic cell injury to these organs (53-57).

The elevated levels of death ligands TNF- $\alpha$ and Fas in the serum of cardiac surgery patients subjected to $\mathrm{CPB}$ and the indices of myocardial apoptosis activation after CPB and blood cardioplegia, support the evidence for promoted apoptosis secondary to CPB machine function, surgical trauma and hypothermia (11,58-60). Cardiomyocyte apoptosis, which is present in arrested myocardium, seems to be secondary to the remaining myocardial ischemia per se, despite the applied cardioplegic preservation techniques (11).

Myocardial reperfusion subsequent to cardioplegic arrest accelerates the apoptosis cascade, which is triggered by the increased cellular $\mathrm{Ca}^{2+}$ concentration and massive production of oxidative agents $(61,62)$. Aebert et al reported that the patient's serum after $\mathrm{CPB}$ exercises a robust apoptotic activity on human endothelial cells, possibly through the extrinsic pathway, which may consequently provoke the postoperative enhancement of vascular permeability and organ dysfunction in such patients (63).

Considering that apoptosis is a well-regulated process, there is a reliable prospect for pharmacological or genetic intervention to prevent cell death apoptosis and the consequences of myocardial dysfunction associated with cardiac surgery procedures. It has been reported that cardioplegia-induced apoptosis in human left ventricle cadiomyocytes can be effectively prevented using $\mathrm{N}$-acetylcysteine scavenger, which is a promising method that can be applied for myocardial reperfusion injury prevention during cardiac surgery procedures (11).

\section{Principles of cardiomyocyte autophagy}

Myocardial autophagy was first reported in the 1970s (64). The induction of autophagy and the crosstalk to apoptotic mechanisms formulate the 'core' of molecular homeostasis in cardiomyocytes, in terms of a continuous balanced renovation for the removal and replacement of damaged cell elements $(31,65)$. In response to severe stress stimuli, autophagy induction may trigger either apoptotic or necrotic cell death, indicating the crosstalk between cellular death mechanisms (66). Mounting evidence indicates that the mechanisms of apoptosis, autophagy and necrosis are linked and interrelated, signifying a new era in the approach of the myocardial cell homeostasis $(65,67-69)$.

In a cohort of myocardial pathologies, including ischemic cardiomyopathy, myocardial hypertrophy, dilated cardiomyophathy and heart failure, activation of the autophagy process modifications reflects either the compensatory mecha- 
nism aimed at increasing the energy supply to cardiomyocytes or to involvement in autophagic programmed cell death $(15,70)$.

Myocardial ischemia-induced autophagy may promote cell survival, thereby preserving cardiomyocyte energy homeostasis. Myocardial regions with increased autophagic activity are exhibited with fewer apoptotic cells, suggesting that the induction of autophagy may prevent apoptosis. Mild ischemic stimuli trigger the autophagic mechanism, whereas severe and sustained ischemia tilt the signaling balance towards apoptosis and necrotic cell death. Mounting evidence supports that autophagy in chronic myocardial ischemia pertains to the cell's compensatory mechanisms aimed at increasing the energy supply to meet cellular demand, and that autophagy augmentation may be a novel strategy on myocardial protection $(16,71)$. Apparently, the process of autophagy that predominately acts as a cytoprotective mechanism has been linked to both modes of cell death (apoptosis and necrosis) and behaves either as a pre-survival or pre-cell death process (72). Cell death following ischemia reperfusion injury appears to be a mixture of apoptosis, autophagic cell death and necrosis, suggesting a lack of borders among the three modes of cell death as well as the crosstalk regulation among them (73). Autophagy impairment is associated with the accumulated misfolded proteins and dysfunctional mitochondria that inversely affect the post-myocardial infarction remodeling process. In clinical practice, autophagy impairment is associated with myocardial ischemia augmentation, and is predisposed to multiple myocardial dysfunctions, including increased risk for arrhythmias, decreased cardiomyocyte contractility reserve, reduced resistance to ischemic reperfusion injury and increased inflammation process (74). Parkin protein deficiency, which reduces mitophagy, is associated with an increase of cardiac remodeling, dysfunctional mitochondria accumulation and reduced survival (70). By contrast, metamorfin administration, a well-known oral diabetes medicine, increases insulin sensitivity and consequently its antidiabetic effect, by activating the adenosine monophosphate (AMP)-activated protein kinase (AMPK) concentration, which in turn promotes autophagy and antioxidant protection (75).

Myocardial hypertrophy is associated with several hypertrophy-related signaling pathways, which are also involved in cardiomyocyte autophagic downregulation (76). Cardiac hypertrophy secondary to systemic hypertension or left ventricular pressure overload is related to attenuation of the cardiomyocyte autophagic process, promoting myocardial mass hypertrophy (77). By contrast, autophagy is activated during the regression of hypertrophy following the appropriate treatment, suggesting the link between cardiomyocyte autophagy and myocardial hypertrophy (78). The development of dilated cardiomyopathy and heart failure is related to advanced apoptotic and autophagic programmed cell death. The molecular mechanism in hypertrophic and dilated cardiomyopathies is associated with distinctive features of the apoptosis, autophagy and necrosis process (79). The remodeling process of compensative hypertrophic cardiomyopathy is associated with reduced autophagy, whereas the induction of the apoptosis process, promotes progressive ventricular dysfunction due to the advanced rate of the cell death process (80). Autophagic Atg5 gene deficiency is associated with myocardial hypertrophy, left ventricular dilatation and contractile dysfunction due to the accumulation of abnormal proteins, which in turn promote ER stress, leading to cell death apoptosis. In addition, $\beta$-adrenergic stimulation that promotes apoptosis and inhibits autophagy leads to myocardial hypertrophy and heart failure $(81,82)$.

In human idiopathic-dilated cardiac failure, the proportion of autophagic, apoptotic and necrotic cell death is 0.08 , 0.002 and $0.06 \%$, respectively, indicating the functional crosstalk of the three cell modes of death. However, whether autophagic activity is a sign of failed cardiomyocyte repair or a pathway leading to the cell death of failing cardiomyocytes is unclear (79). The suggestion that autophagic activity is upregulated in failing myocardium may indicate that adaptive autophagy impedes both the accumulation of abnormal proteins and myocardial dysfunction in failing cardiomyopathy (83). The effectiveness of protective autophagy during myocardial reperfusion injury has been examined during the remodeling process of myocardial infarction. Edified autophagic activity in surviving cardiomycytes of the subacute and chronic phase of myocardial infarction is suggestive to its protective role during post-infarction myocardial remodeling procedures (84).

Reversible myocardial reperfusion injury is associated with adaptive autophagy induction resulting in the preservation of mitochondrial ATP production and promotion of cardiomyocyte survival (85). Irreversible reperfusion injury or 'lethal reperfusion' is associated with non-apoptotic cell death and associated with the autophagy of cell death (86).

The myocardial cell homeostasis lifespan is regulated by the mechanism of autophagy, combating against aging cardiomyopathy $(87,88)$. Early signs of myocardial cell senescence secondary to the intracellular accumulation of misfolded proteins and organelles are associated with the deletion or inhibition of myocardial autophagic genes, including Atg1, Atg7, Atg18 and Beclin1, suggesting the correlation of autophagic attenuation with aging (89). The autophagic process in the aging process is characterized by a gradual weakness to remove the damaged proteins and organelles that have accumulated both extra- and intra-lysosomally. The so-called biologic 'waste' reveals autophagic insufficiency in elderly populations. Consequently, a cohort of age-related cardiovascular diseases, such as hypertension, dyslipidemia, diabetes mellitus and metabolic syndrome, which constitute the major causes of morbidity and mortality in the elderly, may have a molecular association with autophagic insufficiency (90).

Diastolic myocardial dysfunction is relatively common in aged myocardium secondary to the increased cardiomyocyte fibrosis, oxidation and inhibition of sarcoplasmic reticulum (SR) $\mathrm{Ca}^{2+}$ ATPase (SERCA2A) and mitochondrial dysfunction (91). Systolic myocardial dysfunction, also present in the elderly, may represent mitochondrial dysfunction-dependent apoptosis and reduced cardiomyocyte energy production, which is associated with aging populations (92). Consequently it seems in response to oxidative stress stimuli a plethora of cellular signal transduction pathways are tightly regulated by adaptive autophagy preserving myocardial cell homeostasis. In clinical practice, Jahania et al, reported that the activation of adaptive autophagy constitutes the underlying molecular mechanism of $\mathrm{HIR}^{2}$ in response to myocardial ischemic stress stimuli during cardiac surgery procedures (31).

Garcia et al noted the evidence of impaired autophagy mechanism in cardiac surgery patients who developed postoperative 
atrial fibrillation (AF) (93). In addition, Kassiotis et al showed that both transcript and proteins levels of autophagy markers and mediators are decreased in the failing human heart with mechanical unloading with a left ventricular assist device (LVAD) (94). Singh et al have demonstrated the global pattern of autophagy gene activation in human myocardium after acute IR injury in cardiac surgery procedures, supporting the evidence of global autophagy activation to limit cardiac failure in response to myocardial reperfusion injury (95).

\section{Myocardial cell homeostasis in cardiac surgery era}

The classic cardiac surgery era, defined through the use of CPB machine function and myocardial cardioplegic arrest, represents the most controlled scenario for cardiomyocyte homeostatic disturbances due to systemic inflammatory response and reperfusion injury, which involve the whole spectrum of consequences ranging from reversible to irreversible myocardial injury $(53,54,56)$.

Myocardial cell homeostasis instantly after CPB termination constitutes the sequence of molecular interrelated and overlapping mechanisms of apoptosis, autophagy and necrosis that are activated by a plethora of induced inflammatory mediators and gene-related signaling pathways. Despite the myocardial protection-applied techniques during cardiac surgery procedures, the severity and spread of myocardial reperfusion injury mainly depends on the stress stimuli violence, ischemic myocardial time and patient endogenous defense against ischemia-reperfusion injury (96).

Molecular and cellular events following ischemia/reperfusion $(\mathrm{I} / \mathrm{R})$ are extremely complicated, representing the convergence of divergent biological pathways (3). Ischemia increases the concentration of the intracellular ions $\mathrm{Na}^{+}, \mathrm{H}^{+}$ and $\mathrm{Ca}^{2+}$ resulting in tissue acidosis, whereas reperfusion provokes rapid alterations in ion flux resulting in expeditious phonon (PH) renormalization and in enhanced cytoxicity (97). $\mathrm{Ca}^{2+}$ overload, expeditious PH renormalization and ROS accumulation are the stimuli for MPTP, resulting in cell death $(98,99)$.

Early pioneers in cardiac surgery identified the patterns of the systemic patient's 'host' injury after CPB procedures. Kirklin first suggested that the harmful consequences of $\mathrm{CPB}$ were secondary to blood exposure to synthetic surfaces of the bypass circuit that trigger the 'whole body' inflammation response (100).

Subsequent studies have been established regarding CPB-associated systemic inflammatory mediators, including complement activation, release of cytokines, endothelial cell activation, production of oxygen-free radicals, platelet-activating factor (PAF), NO and endothelins, which are responsible for CPB-associated multiple organ injury in cardiac surgery patients $(56,57,101)$. Multiple organ dysfunction encountered in post-bypass syndrome following cardiac surgery procedures, including myocardial, pulmonary, cerebral and renal, suggest the presence of apoptotic injury which accounts for a substantial morbidity and even mortality in cardiac surgery patients $(56,57)$.

Moreover, the use of $\mathrm{CPB}$ and cardioplegic arrest provoke a distinguishable mode of changes in molecular signal transduction pathways to the myocardium, including the upregulation of inflammation activators, apoptotic and stress gene activation, as well as immunoglobulin gene downregulation, which affects post-operative myocardial cell homeostasis and the outcome of cardiac surgery patients (102-104).

Myocardial reperfusion injury in the cardiac surgery era is different from that occurring during myocardial infarction, as myocardial ischemia is primarily a procedural issue, secondary to myocardial cardioplegic arrest, despite the myocardial preservation techniques employed during surgery (105).

Clinically, cardiac surgery procedure-associated I/R injuries often exhibited as arrhythmias, myocardial stunning, low-cardiac output and perioperative myocardial infarction. Biochemical evidence of myocardial injury (e.g., elevated levels of circulating CK-MB and/or troponin) has been clearly associated with adverse outcomes in cardiac surgery patients (106). Histologic evidence of myocardial I/R injury during autopsy was detected in $25-45 \%$ of deceased patients soon after coronary artery surgery (107).

Myocardial stunning or post ischemic dysfunction constitutes an appealing clinical issue that formulates the detrimental consequences of $\mathrm{I} / \mathrm{R}$ injury regarding the postoperative myocardial contractility (97).

The aforementioned term was coined by Braunwald and Kloner for the description of functional alterations occurring after a short period of induced myocardial ischemia (108). Myocardial stunning is the reversible myocardial damage by reperfusion injury and is characterized by viable but non-functional myocardium with normal coronaries. It has been shown to appear after unstable angina, acute myocardial infarction, myocardial interventional and cardiac surgery procedures. The pathology mechanism is poorly understood irrespective of whether the two molecular mechanisms, reactive oxygen species and cytosolic calcium $\mathrm{Ca}^{2+}$ overload concentration, are reasonably applied. Notably, these mechanisms are intensely activated in cell apoptosis. The increasing apoptotic index in myocardial specimens from the left ventricle during cardiac surgery is associated with the depressed myocardial contractility displayed in the early postoperative period. These correlated findings suggest that myocardial apoptosis may promote postoperative myocardial depression, which characterizes myocardial stunning (109). The mentioned data are noteworthy as cardiomyocyte apoptosis and stunned myocardium are associated with ROS generation and disruption of $\mathrm{Ca}^{2+}$ cell homeostasis (12).

Calcium concentration is the principle ion for cardiomyocyte contraction; thus, its homeostasis is of paramount importance for the preservation of myocardial contractility. Raised cytosolic-free $\mathrm{Ca}^{2+}$ and ROS concentration may activate mitochondrial permeability transition (MPT), which induces the release of mitochondrial cytochrome $c$, causing the cell's inability of ATP preservation, thus initiating cell death apoptosis (110).

Myocardial arrhythmias displayed early after CPB termination, may be triggered by the altered cytosolic $\mathrm{Ca}^{2+}$ homeostasis, and are acknowledged as a major cause of death in such patients (111). In addition the first minutes of reperfusion, severe $\mathrm{Ca}^{2+}$ homeostasis dysregulation may promote cell death necrosis, and a controlled or mild homeostasis deregulation may promote cell death apoptosis. It should be mentioned that both apoptosis and autophagy are regulated by $\mathrm{Ca}^{2+}$ concentration (112). Control of the cytosolic $\mathrm{Ca}^{2+}$ overload concentration 
is associated with reperfusion injury reduction ameliorating myocardial protection $(113,114)$. Furthermore, $\mathrm{Ca}^{2+}$ influx and myocardial I/R injury induce calcium-activated proteases (calpains), which are involved in the degradation process of cardiomyocyte contractive proteins, such as troponin I and the calcium cycling responsible proteins, known as SERCA2a and phospholamban (PLB) (115).

Calpain activation has been reported to be a link between overload cytosolic $\mathrm{Ca}^{2+}$ concentration and cell death, resulting in the cleavage of Atg5 autophagy gene, which translocates to mitochondria, binding the apoptotic $\mathrm{Bcl}-2$ gene and thereby stimulating cell apoptosis. These data suggest a considerable crosstalk between autophagy, apoptosis and necrosis cell death during myocardial I/R injury, owing to cytosolic $\mathrm{Ca}^{2+}$ concentration, calpain, caspases, and the Bcl-2 gene family $(69,116)$.

Additionally, cell $\mathrm{Ca}^{2+}$ cycling homeostasis is predominantly regulated by the combined action of SR proteins, known as SR $\mathrm{Ca}^{2+}$-ATPase and PLB. Molecular analysis has identified three isoforms of SR $\mathrm{Ca}^{2+}$-ATPase. The SERCA2a isoform, expressed in the myocardium, predominantly controls the cardiomyocyte $\mathrm{Ca}^{2+}$ influx and efflux load, representing the cornerstone of myocardial cell contraction and relaxation. PLB, which means 'to receive phosphate', is a small phosphoprotein (52 amino acids) termed PLB, from the Greek words 'phosphate' and 'lambano'. Phosphorylation of PLB is associated with an increased rate of $\mathrm{Ca}^{2+}$ uptake in $\mathrm{SR}$, and the suspension of SERCA2a inhibition, resulting in an increase in SR $\mathrm{Ca}^{2+}$ concentration. Dephosphorylation of PLB inhibits the SERCA2a affinity for $\mathrm{Ca}^{2+}$. Moreover, increased levels of the SERCA2a protein during I/R conditions result in the improvement of myocardial contractility and $\mathrm{Ca}^{2+}$-cycling load, preserving myocardial cell homeostasis. By contrast, SERCA2a pump dysregulation is associated with failing cardiomyopathies both in systolic and diastolic phases (117).

Ischemic cardiomyopathies are associated with a reduced rate of cardiomyocyte relaxation due to intracellular $\mathrm{Ca}^{2+}$ hemostasis disturbances, resulting in myocardial diastolic dysfunction and stiffness. Given that cardiomyocyte SERCA2a protein activity may reflect the myocardial ventricular performance, the SERCA2a level reduction and phosphorylation of PLB following CPB, may further elucidate the mechanism of ventricular dysfunction, which is associated with cardiac surgery procedures (118).

In the context of this discussion, thyroid hormone $\mathrm{T}_{3}$ in particular, has the ability to allocate the available cellular $\mathrm{Ca}^{2+}$ towards the myocyte contractile apparatus, thereby avoiding $\mathrm{Ca}^{2+}$ overload myocardial injury (119). $\mathrm{T}_{3}$ administration has been reported to improve left ventricular contractility following CPB by activating $\beta$-adrenergic agonists, receptors or phosphodiesterase inhibitors, resulting in increased levels of cardiomyocyte cyclic adenosine monophosphate (cAMP), indicating a tight relationship between the thyroid and myocardial function $(120,121)$. The underlying molecular mechanism seems to be the involvement of the SERCA/PLB complex, since the administration of thyroid hormone $\left(\mathrm{T}_{3}\right)$ increases both SERCA2a mRNA and the phosphorylation state of PLB, which magnify the speed of contraction and diastolic relaxation of the left ventricular performance $(122,123)$.

On the other hand, insights have been gained regarding the decline of free (f) $T_{3}$ concentrations during the early course following CPB resulting in the 'euthyroid sick syndrome' or 'low $\mathrm{T}_{3}$ syndrome'. It is characterized by total $\mathrm{T}_{3}$ and $\mathrm{fT}_{3}$ depressed concentrations, despite normal thyroid stimulating hormone (TSH) and thyroxine $\mathrm{T}_{4}$ levels $(124,125)$.

The syndrome belongs to the endocrine homeostasis disturbances, which are mostly associated with the catabolic state of cardiac surgery in patients with and without CPB. However, it has been identified in patients with myocardial infarction and heart failure $(126,127)$. Well-documented studies indicate the direct effectiveness of $\mathrm{T}_{3}$ on the sarcolemmal receptor systems that include the L-type $\mathrm{Ca}^{+}$channel and $\beta$-adrenergic receptors of the myocyte, supporting the suggestion that in the presence of $\beta$-adrenergic receptor stimulation, $\mathrm{T}_{3}$ has the capability to regulate intracellular $\mathrm{Ca}^{2+}$ availability directly to the contractile apparatus (120). Given the mentioned mechanism, cumulative lines of evidence provide a strong suggestion that a low $\mathrm{T}_{3}$ state may be associated with a strong predictor of low cardiac output and death in coronary artery bypass grafting (CABG) patients and that the $\mathrm{T}_{3}$ administration as an inotrope adjunct may reduce myocardial damage and stunned myocardium in CABG surgical procedures $(128,129)$. Indeed, a substantial number of randomized trials have reported the improvement of cardiac output, the reduction of inotropes diuretics, the need for intra-aortic balloon pump (IABP) ICU stay, and the incidence of postoperative AF following $\mathrm{T}_{3}$ administration as a therapeutic adjunct in cardiac surgery patients. However, despite the encouraging conclusions regarding the efficacy of $\mathrm{T}_{3}$ administration as an inotropic adjunct for myocardial recovery after cardiac surgery, further research is required for the investigation of potential $\mathrm{T}_{3}$ use-related side-effects with the increase in myocardial oxygen demand in this group of patients $(130,131)$.

Apart from the beneficial effects of thyroid hormone in stunning myocardium, its cytoprotective mechanism on ischemic myocardium is associated with Akt signaling pathway activation, which may increase the phosphorylation state of heat shock proteins (HSP), in particular HSP20. This results in amplification of the endogenous cytoprotective mechanism preserving myocardial contractility (inotropic effect) $(132,133)$. The HSP20 cardioprotective effect against I/R is associated with reduced apoptosis owing to Bax/Bcl-2 and Akt pathway activation (134). The associated improvement in myocardial performance suggests the beneficial effects of HSP20 phosphorylation in myocardial cell homeostasis.

\section{Myocardial homeostasis in current cardiac surgery settings}

The final balance of the delicate myocardial cell homeostatic mechanism during cardiac surgery procedures is mostly defined from postoperative cardiac function and patient outcome. In the settings of current cardiac surgery procedures the surgeon's ultimate purpose, remains myocardial protection against the detrimental effects of reperfusion injury, which has been acknowledged as the cornerstone of successful patient outcome. Cardiac surgery practice uses several myocardial protection techniques, including the administration of intra- vs. extra-cellular or blood-based cardioplegia solutions delivered by ante- or retrograde routes, designated to prevent $\mathrm{Ca}^{2+}$ overload concentration in order 
to provide energy substrates, thereby reducing cellular and subcellular ROS generation to amplify the myocardial defense mechanism, minimizing the ischemic injury in arrested myocardium (135-137). However, despite the meticulously applied cardioprotective techniques, the remaining myocardial ischemia results in the triggering of myocardial apoptosis, imbalance of myocardial cell homeostasis and the development of cardiomyocyte reperfusion injury. In clinical terms, myocardial (I/R) injury subsequent to cardiac surgery procedures is frequently manifested as myocardial arrhythmias, infarction, low cardiac output, or even death $(104,135,138,139)$.

A common clinical scenario encountered early following cardiac surgery is the decline of myocardial performance up to $30-40 \%$ compared to preoperative baseline, which has been referred to as myocardial stunning (109). On the other hand, in cardiac surgery patients, the nadir of myocardial dysfunction is estimated between 4 and $6 \mathrm{~h}$ postoperatively but myocardial depression may last for 30 days (140). Beyond these time references, it has been mentioned that the mortality in CABG patients, with evidence of histologic myocardial reperfusion injury on autopsy, was detected in 25-45\% of patients (107).

In the settings of cardiac surgery procedures, the majority of cardiac surgery patients have a successful outcome. However, it is estimated that $10 \%$ of these patients, who have been subjected to elective and straightforward procedures, are complicated with low cardiac output syndrome requiring optimization of inotrope infusion or even IABP support (141). Long-term and increasing levels of inotropic therapy for cardiac failure in such patients should be avoided since the apoptosis induced by the $\beta$-adrenergic pathway may have a negative impact on myocardial performance, e.g., arrhythmias and desensitization of cardiac $\beta$-adrenergic receptors. Given that the failing myocardial conditions following cardiac surgery procedures, such as low cardiac output and myocardial infarction, are associated with increased levels of endogenous catecholamines, the required inotropic support may follow in the form of alternative medication, such as phosphodiesterase inhibitors, instead of $\beta$-adrenergic receptors, in order to increase the levels of cAMP $(142,143)$.

Sustained postoperative low cardiac output conditions, e.g., stunning myocardium, are characterized by elevated serum levels of angiotensin II secondary to rennin-angiotensin and aldosterone system (RAAS) activation. Angiotensin II is a potent vasoconstrictor octapeptide affecting the systemic organs vascular tone in vivo, including the heart, kidney, brain and endocrine system. In particular, angiotensin II produces myocardial afterload augmentation, induces ventricular remodeling and stimulates the cardiomyocyte process of necrosis and apoptosis secondary to apotogenic gene induction, such as $c$-myc, $c$-fos, $c$-jun and $p 53$ proapoptotic genes $(144,145)$. Consistent with this hypothesis, the use of angiotensin-converting enzyme inhibitors (ACEIs) and angiotensin receptor blockers (ARBs) has been suggested to inhibit apoptotic cell death (146). Thus, it has been demonstrated that the long-term use of ACEIs and ARBs reduces morbidity and mortality in patients with diabetes, cardiovascular and kidney diseases. Nevertheless, its application remains controversial in cardiac surgery patients $(147,148)$.

The use of gloucocorticoids in the settings of cardiac surgery procedures, may have a beneficial effect on the surgical outcome, as it has been shown to mediate the attenuation of reperfusion injury, resulting in the improvement of myocardial protection and the amelioration of post-CPB myocardial function (149).

The underlying mechanism may be related to the maintenance of calpastatin, the endogenous calpan inhibitor, which directly ameliorates $\mathrm{Ca}^{2+}$ dynamics in cardiomyocyte and minimizes myocardial (I/R) injury (150).

In addition, short-term pretreatment with steroids in CABG patients has been demonstrated to reduce the incidence of postoperative AF by $50 \%$. The molecular mechanism was found to be related to the mitigation of IL- 6 inflammatory mediator associated with the CPB systemic inflammatory response (151).

The issue for the optimal time for mechanical support (IABP, ventricular assist devices) initiation in failing hearts following cardiac surgery is a matter of surgical judgment, given the harmful effects of the extended inotropic support in such patients. Late initiation of mechanical support may have no beneficial effect on myocardial recovery since after a prolonged period of inotropic therapy an irreversible status of cardiac failure, 'burned out myocardium', may be caused, secondary to apoptotic cell death. By contrast, early mechanical support may increase the likelihood of myocardial recovery by limiting the induced myocardial apoptosis (152-154).

The acknowledgement that the majority of cardiac surgery patients recover from reperfusion injury suggests that the individual response to the CPB-associated cardiomyocyte homeostatic disturbances varies from person to person and it attests the patient's endogenous defense mechanism against the widespread consequences of (I/R) injury $(12,13)$.

It has also been validated that in patients with preoperative risk factors that limit the physiologic reserve against cardiac surgery-associated stress stimuli, such as the elderly, as well as those with systemic comorbidities, impaired left ventricular injection fraction or those who need lengthy CPB period, the risk of postoperative mortality exceeds $11 \%$ (9).

Additionally, the presence of preoperative comorbidities, including obesity, metabolic syndrome or advanced age, compromise the patient's tolerance against reperfusion injury, as a consequence of the adaptive autophagic process restriction, resulting in the impairment of myocardial $\operatorname{HIR}^{2}(30,155,156)$. In other words, the reported improvement of the cardiac surgery outcome following modification of preoperative comorbidities (157), may be credited to the amplification of myocardial $\mathrm{HIR}^{2}$ and myocardial endogenous protective mechanisms in these patients $(19,31,158)$.

In addition, given the lifespan extension in the last few decades and the further expectation of life prolongation in the coming years, the prevalence of age-related diseases, such as cardiac diseases, are expected to increase in the aging population $(1,2)$. Despite the recent advances in the medical treatment of heart diseases, the substantial cohort of patients requiring surgical treatment, particularly the elderly, is due to increase. As already mentioned, cardiac aging is associated with myocardial hypertrophy, fibrosis, diastolic dysfunction, the accumulation of misfolded proteins and dysfunctional mitochondria as a result of cardiomyocyte autophagy attenuation $(73,88)$. Consequently, the exhausted autophagy in aging, strengthens the concept that the increased susceptibility to 
myocardial injury in the elderly population, is related to the impairment of the autophagic process $(158,159)$.

Additionally in view of the fact that in the aging population the endogenous cardiomyocyte protective mechanisms are attenuated in response to oxidative stress stimuli, indicates a reasonable link between the cell's adaptive autophagic dysregulation, the loss of cardiomyocyte homeostasis and the postoperative myocardial dysfunction (160). The referred knowledge for the cardiomyocyte adaptive autophagy impairment in the elderly, obese, metabolic syndrome and low left ventricular ejection fraction patients, may suggest the limited tolerance of these individuals, against myocardial reperfusion injury encountered in cardiac surgery procedures.

Notably, the current guidelines for CABG surgery procedures, considering the patient's risk factors, myocardial and the coincidence of systemic co-morbidities, introduced the 'heart team' concept for a balanced multidisplinary preoperative evaluation, in order that the surgical strategy be individualized for each patient, ameliorating the surgical outcome (161).

The mentioned discussion for the spectrum of myocardial homeostasis mechanisms in the settings of cardiac surgery procedures, may support at a molecular level clinical the dictum by Dr Sabic: 'Fit the operation to the patient, not the patient to the operation'. Specifically, he proposed the metioned concept, emphasizing the significance of surgical judgment to tailor the surgical treatment to the patient's individual characteristics such as age, and co-morbidities. This strategy make the particular procedure more likely to be successful (162).

\section{Conclusions}

The present study has outlined the available knowledge regarding the cardiomyocyte adaptive homeostatic mechanism, and the patient's individual endogenous defense mechanism against myocardial reperfusion injury in the settings of cardiac surgery procedures. Myocardial homeostasis in relation to myocardial protection in cardiac surgery, remains an evolutionarily molecular and clinical research issue. Moreover, it is emphasized that the planned cardiac surgical treatment has to be individualized according to the patient's preoperative clinical characteristics (age, co-morbidities) that makes the particular procedure more likely to be successful.

\section{References}

1. Lutz W, Sanderson W and Scherbov S: The coming acceleration of global population ageing. Nature 451: 716-719, 2008.

2. Mozaffarian D, Benjamin EJ, Go AS, Arnett DK, Blaha MJ, Cushman M, de Ferranti S, Després JP, Fullerton HJ, Howard VJ, et al; American Heart Association Statistics Committee and Stroke Statistics Subcommittee: Heart disease and stroke statistics-2015 update: A report from the American Heart Association. Circulation 131: e29-e322, 2015.

3. Turer AT and Hill JA: Pathogenesis of myocardial ischemia-reperfusion injury and rationale for therapy. Am J Cardiol 106: 360-368, 2010.

4. Whelan RS, Kaplinskiy V and Kitsis RN: Cell death in the pathogenesis of heart disease: Mechanisms and significance. Annu Rev Physiol 72: 19-44, 2010.

5. Chiong M, Wang ZV, Pedrozo Z, Cao DJ, Troncoso R, Ibacache M, Criollo A, Nemchenko A, Hill JA and Lavandero S: Cardiomyocyte death: Mechanisms and translational implications. Cell Death Dis 2: e244, 2011.

6. Marunouchi T and Tanonaka K: Cell death in the cardiac myocyte. Biol Pharm Bull 38: 1094-1097, 2015.
7. Tavernarakis N: Cardiomyocyte necrosis: Alternative mechanisms, effective interventions. Biochim Biophys Acta 1773: 480-482, 2007.

8. Golstein P and Kroemer G: Cell death by necrosis: Towards a molecular definition. Trends Biochem Sci 32: 37-43, 2007.

9. Khoynezhad A, Jalali Z and Tortolani AJ: Apoptosis: Pathophysiology and therapeutic implications for the cardiac surgeon. Ann Thorac Surg 78: 1109-1118, 2004.

10. Anselmi A, Abbate A, Girola F, Nasso G, Biondi-Zoccai GG, Possati $\mathrm{G}$ and Gaudino M: Myocardial ischemia, stunning, inflammation, and apoptosis during cardiac surgery: A review of evidence. Eur J Cardiothorac Surg 25: 304-311, 2004.

11. Fischer UM, Klass O, Stock U, Easo J, Geissler HJ, Fischer JH, Bloch W and Mehlhorn U: Cardioplegic arrest induces apoptosis signal-pathway in myocardial endothelial cells and cardiac myocytes. Eur J Cardiothorac Surg 23: 984-990, 2003.

12. Schmitt JP, Schröder J, Schunkert H, Birnbaum DE and Aebert H: Role of apoptosis in myocardial stunning after open heart surgery. Ann Thorac Surg 73: 1229-1235, 2002.

13. Gatica D, Chiong M, Lavandero S and Klionsky DJ2: Molecular mechanisms of autophagy in the cardiovascular system. Circ Res 116: 456-467, 2015.

14. Jia G and Sowers J: Autophagy: A housekeeper in cardiorenal metabolic health and disease. Biochim Biophys Acta 1852: 219-224, 2015.

15. Martinet W, Knaapen MW, Kockx MM and De Meyer GRY: Autophagy in cardiovascular disease. Trends Mol Med 13: 482-491, 2007.

16. Levine B and Kroemer G: Autophagy in the pathogenesis of disease. Cell 132: 27-42, 2008.

17. Ravikumar B, Sarkar S, Davies JE, Futter M, Garcia-Arencibia M, Green-Thompson ZW, Jimenez-Sanchez M, Korolchuk VI, Lichtenberg M, Luo S, et al: Regulation of mammalian autophagy in physiology and pathophysiology. Physiol Rev 90: 1383-1435, 2010.

18. Levine B, Mizushima N and Virgin HW: Autophagy in immunity and inflammation. Nature 469: 323-335, 2011.

19. Yang L, Li P, Fu S, Calay ES and Hotamisligil GS: Defective hepatic autophagy in obesity promotes ER stress and causes insulin resistance. Cell Metab 11: 467-478, 2010.

20. Jia G and Sowers JR: Autophagy: A housekeeper in cardiorenal metabolic health and disease. Biochim Biophys Acta 1852: 219-224, 2015.

21. Riehle C, Wende AR, Sena S, Pires KM, Pereira RO, Zhu Y, Bugger H, Frank D, Bevins J, Chen D, et al: Insulin receptor substrate signaling suppresses neonatal autophagy in the heart. J Clin Invest 123: 5319-5333, 2013.

22. Levine B and Klionsky DJ: Development by self-digestion: Molecular mechanisms and biological functions of autophagy. Dev Cell 6: 463-477, 2004.

23. Yorimitsu T and Klionsky DJ: Autophagy: Molecular machinery for self-eating. Cell Death Differ 12 (Suppl 2): 1542-1552, 2005.

24. Levine B and Yuan J: Autophagy in cell death: An innocent convict? J Clin Invest 115: 2679-2688, 2005.

25. Yang YP, Liang ZQ, Gu ZL and Qin ZH: Molecular mechanism and regulation of autophagy. Acta Pharmacol Sin 26: 1421-1434, 2005.

26. Kanamori H, Takemura G, Maruyama R, Goto K, Tsujimoto A, Ogino A, Li L, Kawamura I, Takeyama T, Kawaguchi T, et al: Functional significance and morphological characterization of starvation-induced autophagy in the adult heart. Am J Pathol 174: 1705-1714, 2009.

27. Galluzzi L, Pietrocola F, Levine B and Kroemer G: Metabolic control of autophagy. Cell 159: 1263-1276, 2014.

28. Vanlangenakker N, Vanden Berghe T, Krysko DV, Festjens N and Vandenabeele P: Molecular mechanisms and pathophysiology of necrotic cell death. Curr Mol Med 8: 207-220, 2008.

29. Henriquez M, Armisén R, Stutzin A and Quest AF: Cell death by necrosis, a regulated way to go. Curr Mol Med 8: 187-206, 2008.

30. Kroemer G, Galluzzi L and Brenner C: Mitochondrial membrane permeabilization in cell death. Physiol Rev 87: 99-163, 2007.

31. Jahania SM, Sengstock D, Vaitkevicius P, Andres A, Ito BR, Gottlieb RA and Mentzer RM Jr: Activation of the homeostatic intracellular repair response during cardiac surgery. J Am Coll Surg 216: 719-726, discussion 726-729, 2013.

32. Nishida K, Yamaguchi O and Otsu K: Crosstalk between autophagy and apoptosis in heart disease. Circ Res 103: 343-351, 2008.

33. Lavandero S, Chiong M, Rothermel BA and Hill JA: Autophagy in cardiovascular biology. J Clin Invest 125: 55-64, 2015. 
34. Thorburn A: Apoptosis and autophagy: Regulatory connections between two supposedly different processes. Apoptosis 13: 1-9, 2008.

35. Osellame LD, Blacker TS and Duchen MR: Cellular and molecular mechanisms of mitochondrial function. Best Pract Res Clin Endocrinol Metab 26: 711-723, 2012.

36. Seo AY, Joseph AM, Dutta D, Hwang JCY, Aris JP and Leeuwenburgh C: New insights into the role of mitochondria in aging: Mitochondrial dynamics and more. J Cell Sci 123: 2533-2542, 2010.

37. Enari M, Sakahira H, Yokoyama H, Okawa K, Iwamatsu A and Nagata S: A caspase-activated DNase that degrades DNA during apoptosis, and its inhibitor ICAD. Nature 391: 43-50, 1998.

38. Nicholson DW and Thornberry NA: Caspases: Killer proteases. Trends Biochem Sci 22: 299-306, 1997.

39. Quinsay MN, Lee Y, Rikka S, Sayen MR, Molkentin JD, Gottlieb RA and Gustafsson AB: Bnip3 mediates permeabilization of mitochondria and release of cytochrome $\mathrm{c}$ via a novel mechanism. J Mol Cell Cardiol 48: 1146-1156, 2010

40. Oda E, Ohki R, Murasawa H, Nemoto J, Shibue T, Yamashita T, Tokino T, Taniguchi $\mathrm{T}$ and Tanaka N: Noxa, a BH3-only member of the Bcl-2 family and candidate mediator of p53-induced apoptosis. Science 288: 1053-1058, 2000.

41. Lorenzo HK, Susin SA, Penninger J and Kroemer G: Apoptosis inducing factor (AIF): A phylogenetically old, caspase-independent effector of cell death. Cell Death Differ 6: 516-524, 1999.

42. Tanaka M, Nakae S, Terry RD, Mokhtari GK, Gunawan F, Balsam LB, Kaneda H, Kofidis T, Tsao PS and Robbins RC: Cardiomyocyte-specific $\mathrm{Bcl}-2$ overexpression attenuates ischemia-reperfusion injury, immune response during acute rejection, and graft coronary artery disease. Blood 104: 3789-3796, 2004.

43. Thompson CB: Apoptosis in the pathogenesis and treatment of disease. Science 267: 1456-1462, 1995.

44. Saraste A, Voipio-Pulkki LM, Parvinen M and Pulkki K: Apoptosis in the heart. N Engl J Med 336: 1025-1026, 1997.

45. Kang PM and Izumo S: Apoptosis and heart failure: A critical review of the literature. Circ Res 86: 1107-1113, 2000

46. Olivetti G, Abbi R, Quaini F, Kajstura J, Cheng W, Nitahara JA, Quaini E, Di Loreto C, Beltrami CA, Krajewski S, et al: Apoptosis in the failing human heart. N Engl J Med 336: 1131-1141, 1997.

47. Saraste A, Pulkki K, Kallajoki M, Henriksen K, Parvinen M and Voipio-Pulkki LM: Apoptosis in human acute myocardial infarction. Circulation 95: 320-323, 1997.

48. Kim NH and Kang PM: Apoptosis in cardiovascular diseases: Mechanism and clinical implications. Korean Circ J 40: 299-305, 2010.

49. Olivetti G, Quaini F, Sala R, Lagrasta C, Corradi D, Bonacina E, Gambert SR, Cigola E and Anversa P: Acute myocardial infarction in humans is associated with activation of programmed myocyte cell death in the surviving portion of the heart. J Mol Cell Cardiol 28: 2005-2016, 1996

50. Kalra M and Miller VM: Early remodeling of saphenous vein grafts: Proliferation, migration and apoptosis of adventitial and medial cells occur simultaneously with changes in graft diameter and blood flow. J Vasc Res 37: 576-584, 2000.

51. Kovacević M, Simić O, Jonjić N and Stifter S: Apoptosis and cardiopulmonary bypass. J Card Surg 22: 129-134, 2007.

52. Vaage $J$ and Valen G: Pathophysiology and mediators of ischemia-reperfusion injury with special reference to cardiac surgery. A review. Scand J Thorac Cardiovasc Surg Suppl 41: 1-18, 1993.

53. Royston D: The inflammatory response and extracorporeal circulation. J Cardiothorac Vasc Anesth 11: 341-354, 1997.

54. Beal AL and Cerra FB: Multiple organ failure syndrome in the 1990s. Systemic inflammatory response and organ dysfunction. JAMA 271: 226-233, 1994.

55. Wu ZK, Laurikka J, Saraste A, Kytö V, Pehkonen EJ, Savunen T and Tarkka MR: Cardiomyocyte apoptosis and ischemic preconditioning in open heart operations. Ann Thorac Surg 76: 528-534, 2003.

56. Boyle EM Jr, Pohlman TH, Johnson MC and Verrier ED: Endothelial cell injury in cardiovascular surgery: The systemic inflammatory response. Ann Thorac Surg 63: 277-284, 1997.

57. Moat NE, Shore DF and Evans TW: Organ dysfunction and cardiopulmonary bypass: The role of complement and complement regulatory proteins. Eur J Cardiothorac Surg 7: 563-573, 1993

58. Kawahito K, Misawa Y and Fuse K: Transient rise in serum soluble Fas (APO-1/CD95) in patients undergoing cardiac surgery. Artif Organs 24: 628-631, 2000.
59. Meldrum DR and Donnahoo KK: Role of TNF in mediating renal insufficiency following cardiac surgery: Evidence of a postbypass cardiorenal syndrome. J Surg Res 85: 185-199, 1999.

60. Ramlawi B, Feng J and Mieno S: Indices of apoptosis activation after blood cardioplegia and cardiopulmonary bypass. Circulation 114 (suppl I): I-257-I-263, 2006.

61. Maulik N, Yoshida T and Das DK: Oxidative stress developed during the reperfusion of ischemic myocardium induces apoptosis. Free Radic Biol Med 24: 869-875, 1998.

62. Kruman I, Guo Q and Mattson MP: Calcium and reactive oxygen species mediate staurosporine-induced mitochondrial dysfunction and apoptosis in PC12 cells. J Neurosci Res 51: 293-308, 1998.

63. Aebert H, Cornelius T, Birnbaum DE, Siegel AV, Riegger GA and Schunkert $\mathrm{H}$ : Induction of early immediate genes and programmed cell death following cardioplegic arrest in human hearts. Eur J Cardiothorac Surg 12: 261-267, 1997.

64. Sybers HD, Ingwall J and DeLuca M: Autophagy in cardiac myocytes. Recent Adv Stud Cardiac Struct Metab 12: 453-463, 1976.

65. Nikoletopoulou V, Markaki M, Palikaras K and Tavernarakis N: Crosstalk between apoptosis, necrosis and autophagy. Biochim Biophys Acta 1833: 3448-3459, 2013.

66. Li M, Gao P and Zhang J: Crosstalk between autophagy and apoptosis: Potential and emerging therapeutic targets for cardiac diseases. Int J Mol Sci 17: 332, 2016.

67. Kunapuli S, Rosanio S and Schwarz ER: 'How do cardiomyocytes die?' apoptosis and autophagic cell death in cardiac myocytes. J Card Fail 12: 381-391, 2006

68. Mukhopadhyay S, Panda PK, Sinha N, Das DN and Bhutia SK: Autophagy and apoptosis: Where do they meet? Apoptosis 19: 555-566, 2014

69. Gordy C and He YW: The crosstalk between autophagy and apoptosis: Where does this lead? Protein Cell 3: 17-27, 2012.

70. Kubli DA, Zhang X, Lee Y, Hanna RA, Quinsay MN, Nguyen CK, Jimenez R, Petrosyan S, Murphy AN and Gustafsson AB: Parkin protein deficiency exacerbates cardiac injury and reduces survival following myocardial infarction. J Biol Chem 288: 915-926, 2013

71. Schiattarella GG and Hill JA: Therapeutic targeting of autophagy in cardiovascular disease. J Mol Cell Cardiol 95: 86-93, 2016

72. Mughal W, Dhingra R and Kirshenbaum LA: Striking a balance: Autophagy, apoptosis, and necrosis in a normal and failing heart. Curr Hypertens Rep 14: 540-547, 2012.

73. Konstantinidis K, Whelan RS and Kitsis RN: Mechanisms of cell death in heart disease. Arterioscler Thromb Vasc Biol 32: 1552-1562, 2012

74. Linton P-J, Gurney M, Sengstock D, Mentzer RM Jr and Gottlieb RA: This old heart: Cardiac aging and autophagy. J Mol Cell Cardiol 83: 44-54, 2015

75. McMullen JR, Sherwood MC, Tarnavski O, Zhang L, Dorfman AL, Shioi $\mathrm{T}$ and Izumo S: Inhibition of mTOR signaling with rapamycin regresses established cardiac hypertrophy induced by pressure overload. Circulation 109: 3050-3055, 2004.

76. Nakai A, Yamaguchi O, Takeda T, Higuchi Y,Hikoso S, Taniike M, Omiya S, Mizote I, Matsumura Y, Asahi M, et al: The role of autophagy in cardiomyocytes in the basal state and in response to hemodynamic stress. Nat Med 13: 619-624, 2007.

77. Frenzel H, Schwartzkopff B, Rettig B and Vogelsang $\mathrm{H}$ Morphologic criteria of progression and regression of cardiac hypertrophy. J Cardiovasc Pharmacol 10 (Suppl 6): S20-S28, 1987.

78. Zhou L, Ma B and Han X: The role of autophagy in angiotensin II-induced pathological cardiac hypertrophy. J Mol Endocrinol 57: R143-R152, 2016.

79. Kostin S, Pool L, Elsässer A, Hein S, Drexler HC, Arnon E, Hayakawa Y, Zimmermann R, Bauer E, Klövekorn WP and Schaper J: Myocytes die by multiple mechanisms in failing human hearts. Circ Res 92: 715-724, 2003.

80. Diwan A and Dorn GW II: Decompensation of cardiac hypertrophy: Cellular mechanisms and novel therapeutic targets. Physiology (Bethesda) 22: 56-64, 2007.

81. Radoshevich L, Murrow L, Chen N, Fernandez E, Roy S, Fung C and Debnath J: ATG12 conjugation to ATG3 regulates mitochondrial homeostasis and cell death. Cell 142: 590-600, 2010.

82. Singh K, Communal C, Sawyer DB and Colucci WS: Adrenergic regulation of myocardial apoptosis. Cardiovasc Res 45: 713-719, 2000.

83. Nishida K, Kyoi S, Yamaguchi O, Sadoshima J and Otsu K: The role of autophagy in the heart. Cell Death Differ 16: 31-38, 2009. 
84. Kanamori H, Takemura G, Goto K, Maruyama R, Tsujimoto A, Ogino A, Takeyama T, Kawaguchi T, Watanabe T, Fujiwara T, et al: The role of autophagy emerging in postinfarction cardiac remodelling. Cardiovasc Res 91: 330-339, 2011.

85. Matsui Y, Kyoi S, Takagi H, Hsu CP, Hariharan N, Ago T, Vatner SF and Sadoshima J: Molecular mechanisms and physiological significance of autophagy during myocardial ischemia and reperfusion. Autophagy 4: 409-415, 2008.

86. Rifki OF and Hill JA: Cardiac autophagy: Good with the bad. J Cardiovasc Pharmacol 60: 248-252, 2012.

87. Gustafsson AB and Gottlieb RA: Recycle or die: The role of autophagy in cardioprotection. J Mol Cell Cardiol 44: 654-661, 2008.

88. Terman A and Brunk UT: Autophagy in cardiac myocyte homeostasis, aging, and pathology. Cardiovasc Res 68: 355-365, 2005.

89.Dutta D, Calvani R, Bernabei R, Leeuwenburgh C and Marzetti E: Contribution of impaired mitochondrial autophagy to cardiac aging: Mechanisms and therapeutic opportunities Circ Res 110: 1125-1138, 2012.

90. Taneike M, Yamaguchi O, Nakai A, Hikoso S, Takeda T, Mizote I, Oka T, Tamai T, Oyabu J, Murakawa T, et al: Inhibition of autophagy in the heart induces age-related cardiomyopathy. Autophagy 6: 600-606, 2010.

91. Qin F, Siwik DA, Lancel S, Zhang J, Kuster GM, Luptak I, Wang L, Tong X, Kang YJ, Cohen RA and Colucci WS: Hydrogen peroxide-mediated SERCA cysteine 674 oxidation contributes to impaired cardiac myocyte relaxation in senescent mouse heart. J Am Heart Assoc 2: e000184, 2013.

92. Newman AB, Arnold AM, Naydeck BL, Fried LP, Burke GL, Enright P, Gottdiener J, Hirsch C, O'Leary D and Tracy R Cardiovascular Health Study Research Group: 'Successful aging': Effect of subclinical cardiovascular disease. Arch Intern Med 163: 2315-2322, 2003.

93. Garcia L, Verdejo HE, Kuzmicic J, Zalaquett R, Gonzalez S, Lavandero S and Corbalan R: Impaired cardiac autophagy in patients developing postoperative atrial fibrillation. J Thorac Cardiovasc Surg 143: 451-459, 2012.

94. Kassiotis C, Ballal K, Wellnitz K, Vela D, Gong M, Salazar R, Frazier $\mathrm{OH}$ and Taegtmeyer H: Markers of autophagy are downregulated in failing human heart after mechanical unloading. Circulation 120 (Suppl): S191-S197, 2009.

95. Singh KK, Yanagawa B, Quan A, Wang R, Garg A, Khan R, Pan Y, Wheatcroft MD, Lovren F, Teoh $\mathrm{H}$ and Verma $\mathrm{S}$ Autophagy gene fingerprint in human ischemia and reperfusion. J Thorac Cardiovasc Surg 147: 1065-1072.e1, 2014.

96. Paparella D, Yau TM and Young E: Cardiopulmonary bypass induced inflammation: Pathophysiology and treatment. An update. Eur J Cardiothorac Surg 21: 232-244, 2002.

97. Frank A, Bonney M, Bonney S, Weitzel L, Koeppen M and Eckle T: Myocardial ischemia reperfusion injury: From basic science to clinical bedside. Semin Cardiothorac Vasc Anesth 16 $123-132,2012$

98. Chen X, Zhang X, Kubo H, Harris DM, Mills GD, Moyer J, Berretta R, Potts ST, Marsh JD and Houser SR: $\mathrm{Ca}^{2+}$ influx-induced sarcoplasmic reticulum $\mathrm{Ca}^{2+}$ overload causes mitochondrial-dependent apoptosis in ventricular myocytes Circ Res 97: 1009-1017, 2005.

99. Di Lisa F and Bernardi P: Mitochondria and ischemia-reperfusion injury of the heart: Fixing a hole. Cardiovasc Res 70 191-199, 2006.

100.Kirklin JK: Prospects for understanding and eliminating the deleterious effects of cardiopulmonary bypass. Ann Thorac Surg 51: 529-531, 1991

101. Westaby S: Organ dysfunction after cardiopulmonary bypass. A systemic inflammatory reaction initiated by the extracorporeal circuit. Intensive Care Med 13: 89-95, 1987.

102. Landis RC, Brown JR, Fitzgerald D, Likosky DS, ShoreLesserson L, Baker RA and Hammon JW: Attenuating the systemic inflammatory response to adult cardiopulmonary bypass: A critical review of the evidence base. J Extra Corpor Technol 46: 197-211, 2014.

103. Ruel M, Bianchi C, Khan TA, Xu S, Liddicoat JR, Voisine P, Araujo E, Lyon H, Kohane IS, Libermann TA and Sellke FW: Gene expression profile after cardiopulmonary bypass and cardioplegic arrest. J Thorac Cardiovasc Surg 126: 1521-1530, 2003.

104. Vähäsilta T, Saraste A, Kytö V, Malmberg M, Kiss J, Kentala E, Kallajoki M and Savunen T: Cardiomyocyte apoptosis after antegrade and retrograde cardioplegia. Ann Thorac Surg 80: 2229-2234, 2005
105. Suleiman MS, Zacharowski K and Angelini GD: Inflammatory response and cardioprotection during open-heart surgery: The importance of anaesthetics. Br J Pharmacol 153: 21-33, 2008

106. Klatte K, Chaitman BR, Theroux P, Gavard JA, Stocke K, Boyce S, Bartels C, Keller B and Jessel A; GUARDIAN Investigators (The GUARD during Ischemia Against Necrosis): Increased mortality after coronary artery bypass graft surgery is associated with increased levels of postoperative creatine kinase-myocardial band isoenzyme release: Results from the GUARDIAN trial. J Am Coll Cardiol 38: 1070-1077, 2001.

107. Weman SM, Karhunen PJ, Penttilä A, Järvinen AA and Salminen US: Reperfusion injury associated with one-fourth of deaths after coronary artery bypass grafting. Ann Thorac Surg 70: 807-812, 2000.

108. Braunwald E and Kloner RA: The stunned myocardium: Prolonged, postischemic ventricular dysfunction. Circulation 66 1146-1149, 1982

109. Bolli R: Basic and clinical aspects of myocardial stunning. Prog Cardiovasc Dis 40: 477-516, 1998

110. Ritchie MF, Zhou Y and Soboloff J: Transcriptional mechanisms regulating $\mathrm{Ca}(2+)$ homeostasis. Cell Calcium 49: 314-321, 2011.

111. Koretsune $Y$ and Marban E: Cell calcium in the pathophysiology of ventricular fibrillation and in the pathogenesis of postarrhythmic contractile dysfunction. Circulation 80: 369-379, 1989.

112. Pinton P, Giorgi C, Siviero R, Zecchini E and Rizzuto R Calcium and apoptosis: ER-mitochondria $\mathrm{Ca}^{2+}$ transfer in the control of apoptosis. Oncogene 27: 6407-6418, 2008.

113. Marks AR: Calcium and the heart: A question of life and death. J Clin Invest 111: 597-600, 2003.

114. Piper HM, Abdallah Y and Schäfer C: The first minutes of reperfusion: A window of opportunity for cardioprotection. Cardiovasc Res 61: 365-371, 2004.

115. French JP, Quindry JC, Falk DJ, Staib JL, Lee Y, Wang KK and Powers SK: Ischemia-reperfusion-induced calpain activation and SERCA2a degradation are attenuated by exercise training and calpain inhibition. Am J Physiol Heart Circ Physiol 290: H128-H136, 2006.

116. Høyer-Hansen M, Bastholm L, Szyniarowski P, Campanella M, Szabadkai G, Farkas T, Bianchi K, Fehrenbacher N, Elling F, Rizzuto R, et al: Control of macroautophagy by calcium, calmodulin-dependent kinase kinase-beta, and Bcl-2. Mol Cell 25: 193-205, 2007.

117. Kranias EG and Hajjar RJ: Modulation of cardiac contractility by the phospholamban/SERCA2a regulatome. Circ Res 110: 1646-1660, 2012.

118. Chen Y, Escoubet B, Prunier F, Amour J, Simonides WS, Vivien B, Lenoir C, Heimburger M, Choqueux C, Gellen B, et al: Constitutive cardiac overexpression of sarcoplasmic/endoplasmic reticulum $\mathrm{Ca}^{2+}$-ATPase delays myocardial failure after myocardial infarction in rats at a cost of increased acute arrhythmias. Circulation 109: 1898-1903, 2004.

119. Walker JD, Crawford FA Jr, Mukherjee R and Spinale FG: The direct effects of 3,5,3'-triiodo-L-thyronine (T3) on myocyte contractile processes. Insights into mechanisms of action. J Thorac Cardiovasc Surg 110: 1369-1379, discussion 1379-1380, 1995.

120. Walker JD, Crawford FA Jr, Mukherjee R, Zile MR and Spinale FG: Direct effects of acute administration of 3, 5, 3 triiodo-L-thyronine on myocyte function. Ann Thorac Surg 58 851-856, 1994

121. Khoury SF, Hoit BD, Dave V, Pawloski-Dahm CM, Shao Y, Gabel M, Periasamy M and Walsh RA: Effects of thyroid hormone on left ventricular performance and regulation of contractile and $\mathrm{Ca}(2+)$-cycling proteins in the baboon. Implications for the force-frequency and relaxation-frequency relationships. Circ Res 79: 727-735, 1996.

122. Fargnoli AS, Katz MG, Yarnall C, Isidro A, Petrov M, Steuerwald N, Ghosh S, Richardville KC, Hillesheim R, Williams RD, et al: Cardiac surgical delivery of the sarcoplasmic reticulum calcium ATPase rescues myocytes in ischemic heart failure. Ann Thorac Surg 96: 586-595, 2013.

123. Pantos C, Mourouzis I, Saranteas T, Clavé G, Ligeret H, Noack-Fraissignes P, Renard PY, Massonneau M, Perimenis P, Spanou D, et al: Thyroid hormone improves postischaemic recovery of function while limiting apoptosis: A new therapeutic approach to support hemodynamics in the setting of ischaemia-reperfusion? Basic Res Cardiol 104: 69-77, 2009.

124. Holland FW II, Brown PS Jr, Weintraub BD and Clark RE Cardiopulmonary bypass and thyroid function: A 'euthyroid sick syndrome'. Ann Thorac Surg 52: 46-50, 1991 
125. Iervasi G, Pingitore A, Landi P, Raciti M, Ripoli A, Scarlattini M, L'Abbate A and Donato L: Low-T3 syndrome: A strong prognostic predictor of death in patients with heart disease. Circulation 107: 708-713, 2003.

126. Ranasinghe AM and Bonser RS: Thyroid hormone in cardiac surgery. Vascul Pharmacol 52: 131-137, 2010.

127. Galli E, Pingitore A and Iervasi G: The role of thyroid hormone in the pathophysiology of heart failure: Clinical evidence. Heart Fail Rev 15: 155-169, 2010.

128. Cerillo AG, Storti S, Kallushi E, Haxhiademi D, Miceli A, Murzi M, Berti S, Glauber M, Clerico A and Iervasi G: The low triiodothyronine syndrome: A strong predictor of low cardiac output and death in patients undergoing coronary artery bypass grafting. Ann Thorac Surg 97: 2089-2095, 2014.

129. Ranasinghe AM, Quinn DW, Pagano D, Edwards N, Faroqui M, Graham TR, Keogh BE, Mascaro J, Riddington DW, Rooney SJ, et al: Glucose-insulin-potassium and tri-iodothyronine individually improve hemodynamic performance and are associated with reduced troponin I release after on-pump coronary artery bypass grafting. Circulation 114 (Suppl): I245-I250, 2006.

130.Portman MA, Slee A, Olson AK, Cohen G, Karl T, Tong E, Hastings L, Patel H, Reinhartz O, Mott AR, Mainwaring R, Linam J, Danzi S; TRICC Investigators: Triiodothyronine supplementation in infants and children undergoing cardiopulmonary bypass (TRICC): A multicenter placebo-controlled randomized trial: Age analysis. Circulation 122 (11 Suppl): S224-S233, 2010.

131.Klemperer JD, Klein IL, Ojamaa K, Helm RE, Gomez M, Isom $\mathrm{OW}$ and Krieger $\mathrm{KH}$ : Triiodothyronine therapy lowers the incidence of atrial fibrillation after cardiac operations. Ann Thorac Surg 61: 1323-1327, discussion 1328-1329, 1996.

132. Novitzky D and Cooper DK: Thyroid hormone and the stunned myocardium. J Endocrinol 223: 1-8, 2014.

133. Mourouzis I, Mantzouratou P, Galanopoulos G, Kostakou E Roukounakis N, Kokkinos AD, Cokkinos DV and Pantos C: Dose-dependent effects of thyroid hormone on post-ischemic cardiac performance: Potential involvement of Akt and ERK signalings. Mol Cell Biochem 363: 235-243, 2012.

134.Fan GC, Chu G, Mitton B, Song Q, Yuan Q and Kranias EG: Small heat-shock protein Hsp20 phosphorylation inhibits beta-agonist-induced cardiac apoptosis. Circ Res 94: 1474-1482, 2004.

135. Chambers DJ and Fallouh HB: Cardioplegia and cardiac surgery: Pharmacological arrest and cardioprotection during global ischemia and reperfusion. Pharmacol Ther 127: 41-52, 2010.

136. Yao H, Han X and Han X: The cardioprotection of the insulinmediated PI3K/Akt/mTOR signaling pathway. Am J Cardiovasc Drugs 14: 433-442, 2014.

137. Fan GC, Ren X, Qian J, Yuan Q, Nicolaou P, Wang Y, Jones WK, $\mathrm{Chu} \mathrm{G}$ and Kranias EG: Novel cardioprotective role of a small heat-shock protein, Hsp20, against ischemia/reperfusion injury. Circulation 111: 1792-1799, 2005.

138. Suleiman MS, Hancock M, Shukla R, Rajakaruna C and Angelini GD: Cardioplegic strategies to protect the hypertrophic heart during cardiac surgery. Perfusion 26 (Suppl 1): 48-56, 2011

139. Habertheuer A, Kocher A, Laufer G, Andreas M, Szeto WY, Petzelbauer P, Ehrlich M and Wiedemann D: Cardioprotection: A review of current practice in global ischemia and future translational perspective. BioMed Res Int 2014: 325725, 2014

140.Juhl-Olsen P, Bhavsar R, Frederiksen CA, Sloth E and Jakobsen CJ: Systolic heart function remains depressed for at least 30 days after on-pump cardiac surgery. Interact Cardiovasc Thorac Surg 15: 395-399, 2012.

141. Breisblatt WM1, Stein KL, Wolfe CJ, Follansbee WP, Capozzi J, Armitage JM and Hardesty RL: Acute myocardial dysfunction and recovery: A common occurrence after coronary bypass surgery. J Am Coll Cardiol 15: 1261-1269, 1990.

142.Lefkowitz RJ, Rockman HA and Koch WJ: Catecholamines, cardiac beta-adrenergic receptors, and heart failure. Circulation 101: 1634-1637, 2000.

143. Heringlake M, Wernerus M, Grünefeld J, Klaus S, Heinze H, Bechtel M, Bahlmann L, Poeling J and Schön J: The metabolic and renal effects of adrenaline and milrinone in patients with myocardial dysfunction after coronary artery bypass grafting. Crit Care 11: R51, 2007.

144.Leri A, Claudio PP, Li Q, Wang X, Reiss K, Wang S, Malhotra A, Kajstura J and Anversa P: Stretch-mediated release of angiotensin II induces myocyte apoptosis by activating p53 that enhances the local renin-angiotensin system and decreases the Bcl-2-to-Bax protein ratio in the cell. J Clin Invest 101: 1326-1342, 1998.
145. Kajstura J, Cigola E, Malhotra A, Li P, Cheng W, Meggs LG and Anversa P: Angiotensin II induces apoptosis of adult ventricular myocytes in vitro. J Mol Cell Cardiol 29: 859-870, 1997.

146. Filippatos G and Uhal BD: Blockade of apoptosis by ACE inhibitors and angiotensin receptor antagonists. Curr Pharm Des 9: 707-714, 2003.

147. Disque Al and Neelankavil J: Con: ACE inhibitors should be stopped prior to cardiovascular surgery. J Cardiothorac Vasc Anesth 30: 820-822, 2016.

148. Bhatia M, Arora H and Kumar PA: Pro: ACE inhibitors should be continued perioperatively and prior to cardiovascular operations. J Cardiothorac Vasc Anesth 30: 816-819, 2016.

149.Pearl JM, Plank DM, McLean KM, Wagner CJ and Duffy JY: Glucocorticoids improve calcium cycling in cardiac myocytes after cardiopulmonary bypass. J Surg Res 167: 279-286, 2011.

150. Ho KM and Tan JA: Benefits and risks of corticosteroid prophylaxis in adult cardiac surgery: A dose-response meta-analysis. Circulation 119: 1853-1866, 2009.

151. Prasongsukarn K, Abel JG, Jamieson WR, Cheung A, Russell JA, Walley KR and Lichtenstein SV: The effects of steroids on the occurrence of postoperative atrial fibrillation after coronary artery bypass grafting surgery: A prospective randomized trial. J Thorac Cardiovasc Surg 130: 93-98, 2005.

152. Asou T, Oe M, Tominaga R, Fukamachi K, Morita S, Kishizaki K, Toshima Y, Nakamura Y, Mitani A and Sakamoto M: Optimal timing for application of ventricular assist devices in patients who cannot be weaned from cardiopulmonary bypass. An experimental study. ASAIO Trans 34: 466-469, 1988.

153. Ooka T and Matsui Y: Optimal timing of left ventricular assist device implantation for severe heart failure patients: Focus on end-organ function not hemodynamics. Circ J 76: 1587-1588, 2012.

154. Yoshioka D, Sakaguchi T, Saito S, Miyagawa S, Nishi H, Yoshikawa Y, Fukushima S, Saito T, Daimon T, Ueno T, et al: Predictor of early mortality for severe heart failure patients with left ventricular assist device implantation: Significance of INTERMACS level and renal function. Circ J 76: 1631-1638, 2012.

155. Prasad H, Ryan DA, Celzo MF and Stapleton D: Metabolic syndrome: Definition and therapeutic implications. Postgrad Med 124: 21-30, 2012.

156. Milano CA, White WD, Smith LR, Jones RH, Lowe JE, Smith PK and Van Trigt P III: Coronary artery bypass in patients with severely depressed ventricular function. Ann Thorac Surg 56: 487-493, 1993.

157. Chakravarthy $\mathrm{M}$ : Modifying risks to improve outcome in cardiac surgery: An anesthesiologist's perspective. Ann Card Anaesth 20: 226-233, 2017

158. Ferdinandy P, Schulz R and Baxter GF: Interaction of cardiovascular risk factors with myocardial ischemia/reperfusion injury, preconditioning, and postconditioning. Pharmacol Rev 59: 418-458, 2007.

159. Sciarretta S, Zhai P, Volpe M and Sadoshima J: Pharmacological modulation of autophagy during cardiac stress. J Cardiovasc Pharmacol 60: 235-241, 2012.

160. Sciarretta S, Yee D, Shenoy V, Nagarajan N and Sadoshima J: The importance of autophagy in cardioprotection. High Blood Press Cardiovasc Prev 21: 21-28, 2014.

161. Head SJ, Kaul S, Mack MJ, Serruys PW, Taggart DP, Holmes DR Jr, Leon MB, Marco J, Bogers AJ and Kappetein AP: The rationale for Heart Team decision-making for patients with stable, complex coronary artery disease. Eur Heart J 34: 2510-2518 2013

162. Sabik JF III: Fit the operation to the patient, not the patient to the operation. J Thorac Cardiovasc Surg 150: 1393-1395, 2015.

This work is licensed under a Creative Commons Attribution-NonCommercial-NoDerivatives 4.0 International (CC BY-NC-ND 4.0) License. 